\title{
Parque Natural Municipal da Paisagem Carioca (RJ): ecoturismo e sustentabilidade
}

\author{
Municipal Natural Park of Carioca Landscape (RJ, Brazil): \\ ecotourism and sustainability
}

Laura Sinay, Maria Cristina Fogliatti de Sinay, Ingrid Almeida de Barros Pena

\begin{abstract}
RESUMO
Por conta dos megaeventos, da relativa pacificação da cidade e do consequente aumento do fluxo turístico no Rio de Janeiro, foi previsto que o número de visitantes nas áreas protegidas cariocas duplicará entre 2012 e 2014, trazendo novos desafios à gestão das unidades de conservação do Rio de Janeiro. Assim, diferentes estratégias estão sendo colocadas em prática para aumentar a efetividade da conservação, quais sejam a criação do Mosaico Carioca, grupo gestor que cuida da gestão conjunta das quase trinta áreas protegidas da cidade, a implantação de uma trilha de longo curso e a redefinição dos limites das unidades já criadas. Nesse contexto, a Secretaria Municipal de Meio Ambiente e Conservação do Rio solicitou à Universidade Federal do Estado do Rio de Janeiro - UNIRIO um estudo sobre o uso público e sobre diferentes estratégias de gestão para três unidades justapostas e praticamente abandonadas pelo poder público, as Áreas de Proteção Ambiental dos Morros São João e Babilônia e Leme e Urubu, e do Parque Estadual do Chacrinha. Esse estudo foi $01^{\circ}$ a especificamente diagnosticar os usos dessa 'ilha natural' em meio a urbes carioca e a propor a união dessas três unidades em um Parque, fundamentado nas potencialidades do ecoturismo, incluindo a proteção da natureza, a educação ambiental e a geração de emprego e renda para a população do entorno. Esse Parque, denominado Parque Natural Municipal da Paisagem Carioca, foi criado pelo prefeito do Rio de Janeiro em Junho de 2013, sendo o $1^{\circ}$ no Brasil a ser criado com base em estudos sociais / turísticos e não em estudos biológicos / ambientais, rompendo, assim, um velho paradigma. Este artigo apresenta alguns dos resultados do estudo mencionado. Tendo como foco o uso público atual, a saber ecoturismo, educação ambiental e atividades de lazer ao ar livre, este artigo apresenta as três unidades e avalia cinco diferentes estratégias de gestão.
\end{abstract}

PALAVRAS-CHAVE: Áreas Protegidas; Ecoturismo; Manejo Adaptativo. 


\section{ABSTRACT}

Due to the megaevents planned for the next years, to the pacification of the city and to the consequent increase in the tourism flow visiting the city of Rio de Janeiro, it was foreseen that the number of visitors in the cariocas' protected areas would duplicate between 2012 and 2014, bringing new challenges to the management of the mentioned areas. Thus, different strategies to increase the effectiveness of conservation are being applied. For example, a management group, namely Carioca Mosaic, was established to allow joint management of Rio's thirty protected areas, a long course track is being implemented and the limits of the areas are being redefined. In this context, the Environment and Conservation Department of the Rio de Janeiro City requested to the Federal University of the State of Rio de Janeiro - UNIRIO studies about the public use and management of three protected areas largely abandoned by the public power. These units are: São João and Babilonia Mounts Protected Area, Leme and Urubu Mounts Protected Area and the Chacrinha State Park. This present study is the first one to diagnose the use of this "natural island" and to propose their junction in one Park. This proposal was based on ecotourism potentialities, such as the protection of nature, environmental education and of job and income generation for nearby populations. This article presents the three mentioned protected areas and the evaluation of five different management strategies, pointing out the best one of then, which was the creation of the Municipal Natural Park of the Carioca Landscape, already inaugurated by the major of the Rio de Janeiro City in June 2013. This is the first Brazilian Park created based on tourism social studies and not on environmental and biological research, breaking, thus, an old paradigm. In this paper, the three natural areas are presented and five different managerial strategies are evaluated.

KEYWORDS: Protected Areas; Ecotourism; Adaptive Management.

\section{Contextualização e Objetivo}

Um dos principais atrativos da cidade do Rio de Janeiro é a sua natureza. As áreas naturais brasileiras de interesse turístico estão legalmente protegidas especialmente em Unidades de Conservação (UC) que começaram a ser estabelecidas no país em 1937. A lei federal 9.985 de 2000 estabeleceu o Sistema Nacional de Unidades de Conservação da Natureza (SNUC) que tem como um de seus objetivo ordenar a criação dessas unidades com relação às suas limitações. $E$ as define como

espaço territorial e seus recursos ambientais, incluindo as águas jurisdicionais, com características naturais relevantes, legalmente instituído pelo Poder Público, com objetivos de conservação e limites definidos, sob regime especial de administração, ao qual se aplicam garantias adequadas de proteção.

Estas Unidades devem ser geridas por um Conselho Gestor com a participação da sociedade civil. 
Essa lei estabeleceu que UCs justa e/ou sobrepostas, mesmo quando com objetivos de conservação diferentes, devem ser geridas como Mosaicos, nos quais gestores das diferentes unidades que os compõem discutem e gerem conjuntamente as mesmas (BRASIL, 2000).

Estes Mosaicos de Áreas Protegidas, conforme definido pelo decreto 4340/2002, integram UCs contínuas e evitam a sobreposição de espaços decisórios. Atualmente, já existem 23 Mosaicos no Brasil ${ }^{1}$ tendo sido o primeiro, Mosaico de Tucuruí (PA), criado em 2002 e um dos últimos, 0 Mosaico Carioca-RJ, em 2011.

Apesar de legalmente constituídas e protegidas, pouco progresso houve em relação à proteção e manejo eficiente das UCs, especialmente na América Latina (DOUROJEANNI; PADUA, 2001; ARAUJO, 2012) onde as cidades avançam sem qualquer planejamento sobre áreas ambientalmente sensíveis (PITT; BOULLE, 2010).

As 22 UCs mais bem estruturadas da cidade do Rio de Janeiro, sendo geridas pelas esferas municipal, estadual e federal, encontram-se atualmente sob a gestão do Mosaico Carioca que abrange cerca de $30 \%$ do território municipal e tem como principal desafio propor e implantar mecanismos mais eficientes de gestão para atender os visitantes, cujo número vem crescendo significativamente desde a escolha da cidade como a sede da Copa do Mundo de Futebol (2014) e das Olimpíadas (2016) (URANI; GIAMBIAGI, 2011).

Segundo dados do Ministério de Turismo (2013), este crescimento expressivo de visitas as áreas protegidas é consequência direta das transformações pelas que a cidade está passando: modernização de áreas, revitalização dos transportes públicos urbanos, novos projetos de vias urbanas, instalação de novas redes de tratamento de efluentes e pacificação da cidade com o controle rigoroso do narcotráfico, dentre outras.

De acordo com dados da Fundo Brasileiro para a Biodiversidade FUNBIO (2012), o número de visitantes às áreas protegidas deverá duplicar entre os anos de 2012 e 2014, o que certamente incrementará os efeitos ou impactos negativos nestas áreas, justificando, assim, a necessidade do desenvolvimento e implementação de novas e eficientes estratégias de gestão.

Para melhorar a visitação, a Secretaria de Meio Ambiente e Conservação do Rio de Janeiro - SMAC solicitou à Universidade Federal do Estado do Rio de Janeiro - UNIRIO um estudo prevendo estratégias de gestão para três UCs cariocas justapostas e praticamente abandonadas pelo poder público: as Áreas de Proteção Ambiental - APA dos Morros São João e Babilônia, e do Leme e Urubu e do Parque Estadual do Chacrinha PEC. O resultado desse estudo (apresentado em SINAY et al. 2012) fundamentou a criação em 2013 do Parque Municipal Natural da Paisagem Carioca pelo Decreto № 37.231, sendo este $01^{\circ}$ Parque criado no Brasil com base em estudos sociológicos / turísticos e não nos aprofundados estudos biológicos, como de praxe até então.

O objetivo deste trabalho é descrever estas três unidades desde a perspectiva da visitação e apresentar a discussão que levou à criação do 
Parque Municipal Natural da Paisagem Carioca com a avaliação de cenários previamente propostos e apresentados em encontros técnicos com a Secretaria de Meio Ambiente e Conservação do Rio de Janeiro e com a sociedade civil interessada. Para alcançar este objetivo, este artigo está composto de mais 4 sessões que contém, respectivamente, um referencial teórico sobre UCs e sobre sistemas de gestão ambiental, a metodologia empregada para fins de diagnóstico e proposta de manejo, a descrição das três unidades avaliadas contendo a localização, o inventário da infraestrutura, o perfil dos visitantes, possíveis impactos associados à visitação e anseios dos gestores e dos visitantes, encerrando com as conclusões do trabalho na última sessão.

Esta pesquisa inova pelo seu foco. Tradicionalmente, as UCs são geridas com foco quase que exclusivo nos sistemas naturais. Mas, uma nova abordagem onde o uso público, incluindo atividades de visitação, ecoturismo e educação ambiental, passa a ser o cerne da análise, vem ganhando importância tendo em vista que a qualidade ambiental, via de regra, é o fator mais importante para a sustentabilidade do uso público. Ainda, os estudos clássicos para a tomada de decisões em UC demandam longos períodos de tempo para serem realizados e como, normalmente, o uso público não pode ser suspenso até que as pesquisas sejam concluídas, os impactos negativos vão se acumulando (SINAY, 2008). Assim, as avaliações com foco na visitação vêm ganhando terreno para a tomada de decisões de curto prazo. Essas avaliações, contudo, não descartam a necessidade de estudos clássicos demorados, que continuam sendo importantes. Elas simplesmente auxiliam na organização de uma das principais causas de degradação de UCs, qual seja, o uso desordenado dos atributos naturais.

Conforme expresso por Salvati (2003), ecoturismo é o turismo que se desenvolve em áreas naturais e que concilia as atividades recreativas com a preocupação pela conservação da biodiversidade promovendo a qualidade de vida da população do entorno. Assim sendo, ele pode ser visto como ferramenta essencial para a conservação e valorização dessas áreas naturais, colaborando no conhecimento e respeito aos elementos culturais da localidade, fortalecendo a solidariedade e a corresponsabilidade nas ações comunitárias e a geração e distribuição de renda local (CEBALLOSLASCURAIN, 2005).

\section{Referencial Teórico}

Vários pesquisadores brasileiros vêm desenvolvendo pesquisas relacionadas com o ecoturismo em UCs destacando a importância do Conselho Gestor para o manejo efetivo dessas unidades, assim como da gestão participativa do uso público onde representantes do governo, da sociedade, de instituições de ensino e pesquisa, ONGs, de Agências e operadoras de turismo, de moradores do entorno e de outros setores interessados discutem ações para promover a visitação a estas unidades com o mínimo de impacto negativo no ambiente.

Como exemplos destes desenvolvimentos podem ser mencionados os trabalhos: de Burkowski e Vilas Boas (2014) que apresentam os 
resultados positivos em prol do desenvolvimento regional conseguidos após a constituição do Mosaico Veredas-Pernaçu criado em 2009 na região noroeste de Minas Gerais; de Pellin et al. (2014) que desenvolveram trabalho semelhante ao anteriormente citado para o Parque Estadual da Pedra Branca, maior parque urbano do país localizado na cidade do Rio de Janeiro, destacando como benefícios a proteção de ecossistemas, da biodiversidade, das nascentes e cursos d'água, controle da erosão, melhoria da qualidade de vida de moradores do entorno, promoção de espaços de integração social, apenas para mencionar alguns benefícios; de Minari e Rabinovici (2014) que destacam a importância dos processos participativos para instituir, com sucesso, projetos de turismo de base comunitária; de Paiva e Araújo (2013) onde em trabalho semelhante ao anterior, as autoras discutiram a importância da gestão participativa em unidades de conservação que tem como principal atividade o ecoturismo, como é o caso da APA dos Recifes de Corais, localizada no Rio Grande do Norte, nesta APA as autoras mostram a importância do Conselho Gestor tomar direções que satisfaçam os anseios dos visitantes como forma de proteção do ambiente; de Wanderley-Filha et al. (2013) que apresentam uma revisão bibliográfica e documental sobre Políticas Públicas para o Turismo no contexto de UCs e sobre estratégias de planejamento destas unidades.

Teixeira e Michelin (2013) apresentaram um artigo sobre o manejo de trilhas nas UCs recomendando a disponibilização de informações sobre as mesmas e sobre o comportamento dos visitantes, a instalação de placas interpretativas e o monitoramento contínuo observando a compactação e a erosão do solo e a largura das trilhas, o acúmulo de lixo, atos de vandalismo como pichações, fogueiras e destruição da vegetação.

Em seu artigo, Oliveira e Blos (2012) desenvolveram uma pesquisa bibliográfica abordando os temas desenvolvimento sustentável, comunidades tradicionais, ecoturismo de base comunitária e gestão participativa buscando entender e refletir sobre seus inter-relacionamentos e usos.

Em relação ao processo de gestão, em particular, de gestão ambiental, cabe destacar o livro publicado pela Editora Interciência de Fogliatti et al. (2008) e hoje em sua segunda edição, onde é proposto um sistema de gestão composto de várias etapas, nos moldes do especificado pela Norma Internacional ISO 14001. Nesta obra, além da proposta teórica de um Sistema de Gestão Ambiental, os autores apresentam exemplos práticos direcionados a três setores, sendo um deles, o turismo. Cabe mencionar que este trabalho norteou a pesquisa de campo, assim como ajudou na criação de cenários de manejo.

\section{Metodologia}

Para alcançar o objetivo proposto, esta pesquisa teve início com o reconhecimento das três unidades sob análise, conforme recomendado por Fogliatti et al (2008). Como inexistiam estudos prévios, praticamente todas as informações foram levantadas diretamente em campo. Participaram deste reconhecimento de áreas 20 alunos de Turismo da Unirio em conjunto com a sua orientadora, Professora Laura Sinay. 
Assim, todos os pontos interessantes das três UCs foram visitados, as trilhas percorridas, 43 atores sociais, incluindo visitantes e conselheiros das unidades, além dos dois gestores atuantes foram entrevistados com o intuito de descobrir os perfis dos visitantes, os anseios dos atores sociais envolvidos com essas áreas e os principais desafios da gestão. Para isto, foram construídos questionários semiestruturados que permitiram alinhavar essas características. A amostra utilizada, a qual se agregaram observações dos alunos que colheram informações em campo, parece ser pequena, porém o volume de visitação na época era também muito reduzido por conta da falta de segurança.

Cinco cenários ou estratégias de manejo foram construídos e discutidos ao longo do primeiro semestre de 2012 em conjunto com técnicos da SMAC e atores sociais interessados.

Com as informações coletadas, foi feito um diagnóstico inicial da área estudada. Com esse diagnóstico em mãos, os impactos negativos de diferentes estratégias (cenários) de gestão foram levantados e os cenários avaliados utilizando uma matriz de avaliação de impactos ambientais.

Para fins de inventário foram visitadas as áreas de uso público das UCs sob análise, mapeando trilhas com uso do aplicativo run keeper que permitiu observar larguras, cumprimentos e alturas máximas alcançadas, reconhecendo estruturas turísticas existentes e fazendo registro fotográfico da região.

As trilhas foram classificadas segundo método proposto no website DNA Aventura, especializado no assunto, e que as divide em leves, moderadas, pesadas e muito pesadas de acordo com o tempo de percurso, altura máxima alcançada, exposição ao sol, sinalização, terreno e esforço físico exigido.

Os impactos ambientais negativos associados à visitação foram levantados nas entrevistas e na literatura sobre o tema e confirmados (ou não) nas visitas em campo.

Logo após estas visitas que aconteceram ao longo do primeiro semestre de 2012 foi possível fazer um diagnóstico da situação atual das UCs e ainda propor estratégias de manejo que foram apresentadas e discutidas em público em duas oportunidades, resultando na proposta de cinco cenários ou estratégias de manejo a serem avaliadas com os resultados das entrevistas semiestruturadas e empregando uma escala de Likert de 5 pontos.

Esta avaliação apontou como estratégia eficiente de manejo o cenário que prevê a criação do denominado Parque Natural Municipal da Paisagem Carioca que junta as três UCs, numa única área de proteção ambiental.

\section{Caracterização das UCs}

As Áreas de Proteção Ambiental dos Morros São João e Babilônia, e Leme e Urubu e do Parque Estadual do Chacrinha (PEC) estão localizadas nos bairros de Copacabana, Leme, Urca e Botafogo, na cidade e estado do Rio de Janeiro, Brasil, numa região urbana densamente habitada (Figura 1). 


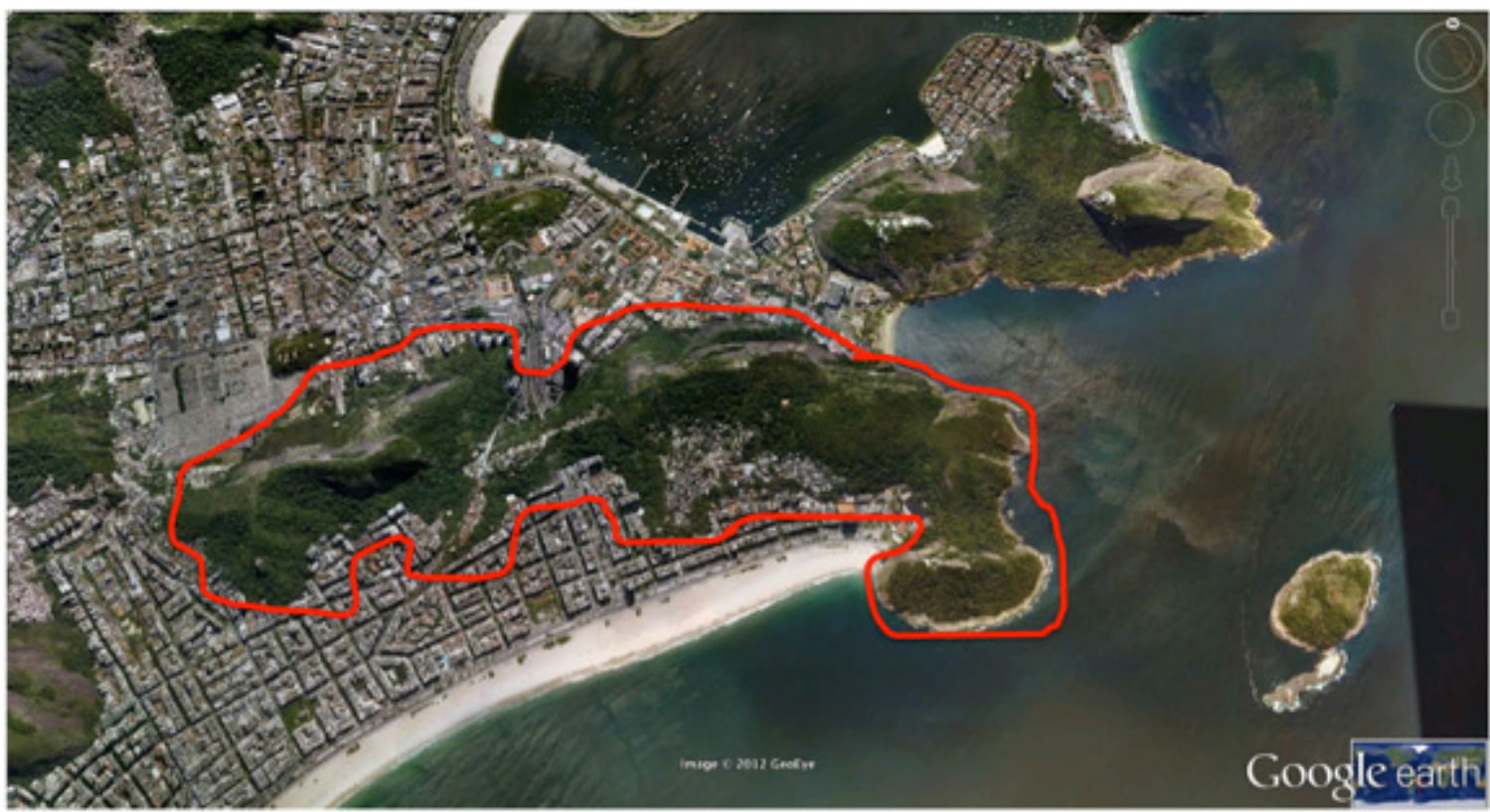

Figura 1: Foto de satélite de toda a área das UCs demarcada. Fonte: Google Earth.

Figure 1: Satelite Picture of the protected areas marked in red. Source: Google Earth.

Estas UCs estão protegidas especificadamente: pelo Decreto Estadual № 2.853/69 que criou o Parque Aldir de Castro Dantas (Chacrinha) - PEC com o objetivo de designar uma área para a coletividade dos bairros de Copacabana e Leme, levando em consideração a densidade demográfica local, e para que, além da preservação do ecossistema natural, possam ser realizadas pesquisas científicas, desenvolvimento de atividades de educação e interpretação ambiental, de recreação em contato com a natureza e de turismo ecológico; pelo Decreto Municipal $N^{\circ} 14.874 / 96$ que estabeleceu a APA dos Morros da Babilônia e de São João com o objetivo de recuperar e preservar a cobertura vegetal existente, preservar e asilar exemplares raros, endêmicos, ameaçados de extinção ou insuficientemente conhecidos da flora e fauna, proteger sítios de excepcional beleza e valor científico, estimular às atividades de lazer, quando compatíveis com os demais objetivos da APA e proteger e valorizar o entorno do bem natural Tombado e pelo Decreto Municipal no. 14.008/1995 que criou a APA do Morro do Leme, Urubu e Ilha de Cotunduba e proibiu o parcelamento do solo em todo território da UC, todas as atividades degradadoras ou potencialmente degradadoras, novas construções, ou mudança do gabarito, na volumetria e no uso das edificações existentes (IPP, 2011; Cadastro Nacional das Unidades de Conservação).

Estas áreas, hoje legalmente protegidas, foram desde o século XIX radicalmente impactadas por fortalezas e outros usos militares, pelo túnel Alaor Prata (que atravessando o Morro da Babilônia une Botafogo à Copacabana), pelo metrô (que passa por baixo do Morro São João e do PEC), pelas favelas (da Chacrinha, removida na década de 1970, Chapéu Mangueira, Leme e Tabajara), pelos edifícios altos que mudaram a dinâmica dos ventos e dos pássaros e pelo despejo de lixo, somente para citar alguns exemplos. Nesse processo, a mata nativa deu lugar a um capinzal que frequentemente se incendiava formando uma enorme e, por vezes, incontrolável fogueira. Na década de 1990, a população do entorno, 
organizada em diferentes grupos como Cooperativa de Trabalhadores em Reflorestamento da Babilonia (CoopBab), ONG Florescer, Exército Brasileiro e Grupo de Ação Ecológica (GAE) deu início ao reflorestamento das áreas (Figuras 2 e 3). Ainda devem ser destacadas outras iniciativas de proteção importantes como a organização do Conselho Gestor da APA e o continuo patrocínio do Shopping Rio Sul.

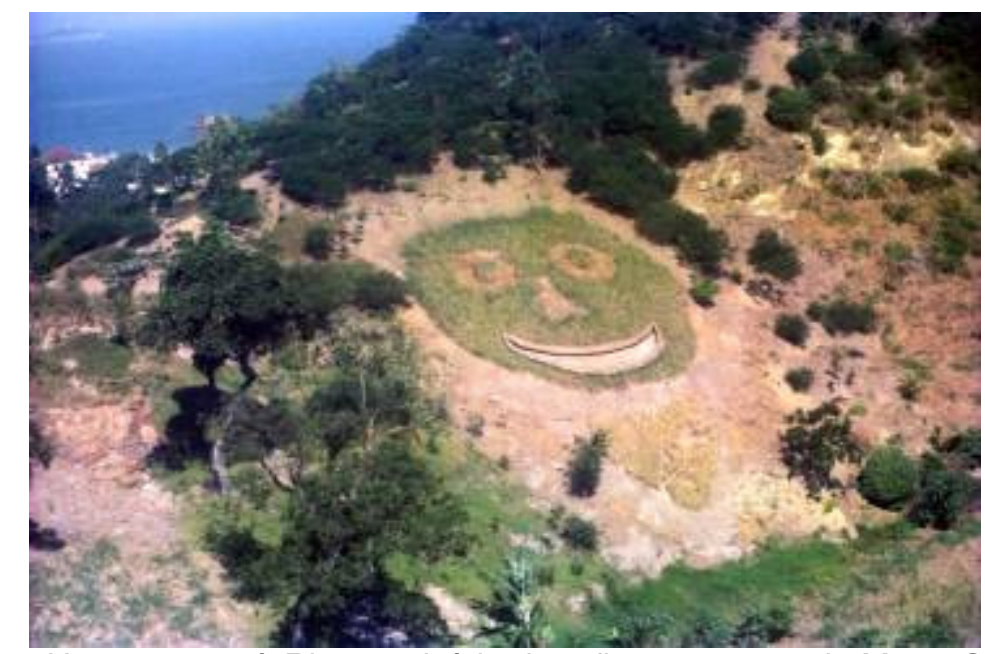

Figura 2: Homenagem à Rio 92 - início do reflorestamento do Morro São João. Figure 2: Homenage to Rio 92 - beginning of reforestation of São João Mountain.

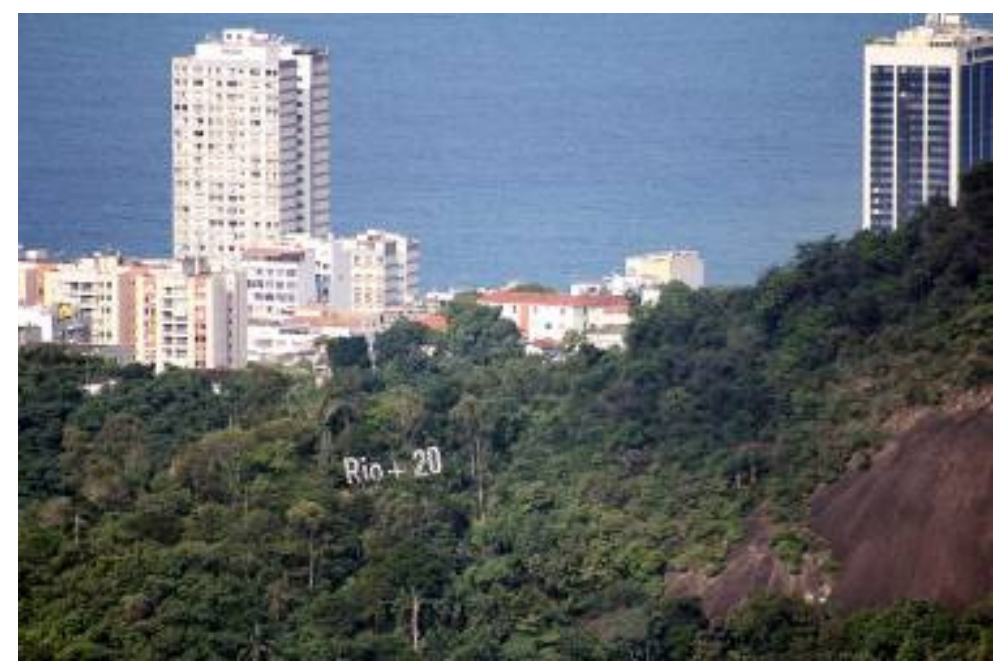

Figura 3: 20 anos depois: Homenagem à Rio + 20 no mesmo local do Happy Face da figura anterior.

Figure 3: 20 years later: tribute to Rio Summit 2012 the same place of the Happy Face of previous picture

Paralelamente à devastação e ao reflorestamento dessa área, a cidade do Rio de Janeiro foi marcada nas últimas décadas pela expansão do crime, especialmente do narcotráfico. Durante esse período, assim como várias outras UCs cariocas, estas também foram utilizadas por criminosos para esconder drogas, armas e corpos e para assaltos, fatos que durante anos inviabilizaram a visitação pública. Finalmente e por conta dos 
megaeventos, a partir de 2009 foram instaladas Unidades de Polícia Pacificadora nos morros da Babilônia, Chapéu Mangueira e Tabajara. A criminalidade, então, diminuiu significativamente nessas UCs e o número de visitantes começou a crescer, assim como as oportunidades de emprego e renda, tanto as derivadas das atividades nas trilhas de educação ambiental, de turismo e de lazer, quanto com estrutura de apoio, como hotéis, restaurantes, vendinhas e "almoços na laje".

As visitas repetidas às áreas sob avaliação alavancaram o inventário das infraestruturas presentes em cada unidade permitindo concluir sobre a carência de estruturas para atividades de lazer e turismo.

O PEC conta com:

- um parquinho razoavelmente novo e bem conservado, que é a área mais utilizada do Parque, especialmente por babás com crianças pequenas;

- uma trilha curta, ruínas do que acredita-se ter sido a casa do primeiro morador de Copacabana, conhecida como a 'casa do pescador', e uma gruta que, segundo contam, foi usada por Tiradentes como refúgio. Esses elementos são usados por caminhantes, pessoas da $3^{a}$ idade, estudantes de escolas próximas e turistas;

- paredes rochosas utilizadas para escalada; e

- uma sede com auditório, escritório, o Museu da Reciclagem e dois banheiros (feminino e masculino).

A única estrutura no Morro São João é um viveiro da ONG Florescer que foi utilizado inicialmente para produção de mudas para o reflorestamento e atualmente para educação ambiental. Além das crianças envolvidas em atividades educativas, também visitam o Morro São João jovens moradores das áreas no entorno para realizar caminhadas em grupos pequenos. Nesse morro existem duas trilhas pouco manejadas que se cruzam em dois locais diferentes e que oferecem vista para o Cristo e para o Pão de Açúcar, para o mar e para a Baía de Guanabara.

O Morro da Babilônia costuma receber turistas nacionais e estrangeiros, além de moradores do Leme. A maior parte das pessoas que faz caminhadas nas trilhas vem por agências de turismo e albergues. Entre as motivações de visitação destacam-se: lazer, pesca, fazer orações, curiosidade de saber como vivem as pessoas que moram no Morro, fazer caminhadas (passeios) nas trilhas, desfrutar das belas paisagens da cidade carioca e, contraditoriamente, usar entorpecentes.

A análise das informações colhidas nos questionários permitiu caracterizar o turismo existente nas áreas estudadas como turismo comunitário, começando com o fim do trabalho de reflorestamento. Os reflorestadores da CoopBab começaram a se especializar no guiamento das trilhas existentes, levando grupos de em média quinze turistas ou, nas datas comemorativas, grupos que chegam a ter mais de cem pessoas. Os reflorestadores da ONG Florescer se especializaram em educação 
ambiental, recebendo no viveiro local turmas de escolas. A principal fonte de captação de turistas para as trilhas do Morro da Babilônia e do Leme é a Chapéu Tour, agência de viagens do Morro Chapéu Mangueira, vizinho à Babilônia. A trilha é operacionalizada pelos condutores da CoopBab, que recebem grupos de variadas idades e um grande percentual de estrangeiros. O Forte Duque de Caxias também oferece uma caminhada ecológica no Morro do Leme, que se diferencia por ir até o sítio histórico do Forte. O tempo médio de caminhada é de trinta minutos e tem um custo de quatro reais. A divulgação é feita por folders, informações em placas nas redondezas e diretamente nas escolas via e-mail.

A comercialização por agências e operadoras de turismo, em geral, ainda é pouca expressiva (Quadro 1), apesar de haver demanda por atividades de trilha na cidade do Rio de Janeiro. Este fato deve-se principalmente à falta de divulgação dessas áreas protegidas por parte dos órgãos de turismo da cidade, intranquilidade das agências quanto à segurança de seus clientes, tanto relacionada à infraestrutura quanto à violência; e aos altos preços cobrados pelas agências que comercializam esses passeios.

Quadro 1: Agências de Turismo.

Quadro 1: Tourism Agencies.

\begin{tabular}{|l|l|}
\hline Agência & Passeio \\
\hline $\begin{array}{l}\text { Bella Tour em } \\
\text { parceria com } \\
\text { Jungle Me }\end{array}$ & $\begin{array}{l}\text { Tour Favela \& Jungle Hike. A trilha é operacionalizada pelos } \\
\text { condutores da CoopBab. O passeio dura em torno de cinco horas } \\
\text { e tem público muito restrito. A agência cobra R } \$ 150,00 \text { por } \\
\text { pessoa. }\end{array}$ \\
\hline $\begin{array}{l}\text { Crux } \\
\text { Aventuras }\end{array}$ & $\begin{array}{l}\text { Comercializa uma caminhada no Morro do Leme, que leva em } \\
\text { torno de três horas - a caminhada começa no final da Avenida } \\
\text { Atlântica próximo ao Forte Duque de Caxias aonde há um } \\
\text { corredor ecológico com vistas inusitadas da Urca e Copacabana. } \\
\text { Existe também a opção de fazer um passeio pela comunidade do } \\
\text { Morro do Leme. Apesar de haver divulgação, a caminhada vende } \\
\text { pouco, pois o foco da empresa é em esportes de aventura. } \\
\text { Ainda assim a caminhada foi criada exatamente para atender o } \\
\text { público que procura passeios diferentes pela cidade do Rio de } \\
\text { Janeiro e aventuras leves. }\end{array}$ \\
\hline CurtiRio & $\begin{array}{l}\text { Agência especializada em montanha, oferece escalada ao Morro } \\
\text { da Babilônia para leigos e experientes. A agência estabelece o } \\
\text { limite de cinco pessoas por grupo, a fim de garantir a qualidade e } \\
\text { segurança do passeio. As atividades são acompanhadas de um } \\
\text { instrutor de escalada em rocha profissional certificado pela } \\
\text { Associação de Guias e Instrutores Profissionais de Escalada do } \\
\text { Rio de Janeiro (AGUIPERJ) e é cobrado entre cem e quinhentos } \\
\text { reais. }\end{array}$ \\
\hline
\end{tabular}

Embora as atividades de turismo e lazer tendam a causar impactos negativos muito menos relevantes do que as atividades que precederam a abertura dessas UCs para visitação pública, a visitação desordenada começa a dar sinais de alargamento das trilhas e aumento do lixo. Outros impactos não foram identificados. 
Visitantes e gestores entrevistados anseiam pela promoção do turismo sustentável, pela educação ambiental, pelo incentivo ao desenvolvimento de pesquisas científicas, pela captação de mais recursos para a melhoria das estruturas existentes e pela promoção das UCs dandoIhes maior visibilidade turística.

Entre os motivos de visitação apontados pelos entrevistados destacam-se a infraestrutura (do PEC), as caminhadas nas trilhas, passeios com crianças, repouso, festas, contato com a natureza, vistas deslumbrantes da cidade, as vias de escaladas, o futebol e a pesca.

Quanto às trilhas, o PEC com uma área de 13,3 hectares de Mata Atlântica possui uma trilha de 1260 metros que pode ser percorrida em aproximadamente 40 minutos. O esforço físico requerido para este percurso não é forte o que classifica a trilha como leve, especialmente por estar quase todo o percurso coberto por árvores o que ameniza a caminhada por um terreno quase todo plano.

A trilha do Morro São João tem um percurso de 2800 metros a ser realizado em 2 horas. Por alcançar uma elevação de 384 metros, o esforço realizado é moderado e a trilha é qualificada da mesma forma.

As trilhas dos Morros Leme e Urubu cujo percurso pode ser realizado em 1 hora alcançando 158 metros de altura e a do Morro da Babilônia que alcança 150 metros de altura e cujo trajeto pode ser feito em uma hora e meia são também classificadas como moderadas, pois partes delas estão expostas ao sol exigindo maior esforço dos visitantes.

Apenas a trilha do Morro da Babilônia tem placas informativas enquanto as restantes ou possuem sinalização escassa ou não possuem qualquer sinalização.

Quanto aos impactos negativos sobre o meio ambiente associados à visitação, nas entrevistas foram apontados o acúmulo de lixo, a erosão e a compactação do solo, a destruição de placas de sinalização existentes. Em visitas a campo apenas os dois primeiros impactos foram efetivamente observados.

\section{Proposta e Análise de Cenários}

As APA dos Morros São João, Babilônia, e do Leme e Urubu e o PEC têm uma história incrível, incluindo períodos de ocupação irregular por camadas menos abastadas da sociedade carioca, de remoção forçada de algumas dessas comunidades, de controle da área por facções de narcotraficantes, do total reflorestamento da região feito de maneira genuinamente comunitária e participativa, de retomada do controle com as unidades de polícia pacificadoras, para chegar agora, no presente, com a perspectiva do turismo, mas sem estrutura para o uso público, mas em contrapartida, com organização social, elemento fundamental para a sustentabilidade do turismo. As possibilidades para o futuro dessas UCs são muitas e vão depender em grande parte das decisões de manejo adotadas no presente. 
A partir das entrevistas e das demandas apresentadas pela SMAC, cinco estratégias de gestão, ou cenários, foram ponderados:

- o $1^{\circ}$ considerou que as unidades continuariam a ser minimamente manejadas, sem planos de manejo ou de uso público, no formato laissez-faire, sem integração entre as áreas;

- o $2^{\circ}$ considerou a junção das três unidades numa só UC, com um único plano de manejo e de uso público para orientar os esforços de gestão;

- o $3^{\circ}$ considerou que as três unidades permaneceriam separadas, mas, como no cenário 2 , contariam com um só plano de uso público;

- a $4^{a}$ estratégia considerou a integração de apenas as duas APA e a manutenção do PEC separado; e

- $\quad$ a $5^{\mathrm{a}}$ considerou a proibição do uso público.

Essas estratégias foram analisadas com o apoio de uma matriz de avaliação de impactos ambientais que permitiu cruzar informação entre cenários e possíveis impactos. O principal fator dessa avaliação foi 0 número de visitantes, cujo aumento restringiria a probabilidade de retorno dos narcotraficantes à área e incrementaria as oportunidades de emprego e renda. Embora as atividades de lazer sejam comumente relacionadas à erosão e compactação das trilhas e ao aumento de riscos à fauna e flora, considerou-se que a visitação é ainda muito reduzida e que o número de visitantes teria que aumentar bastante para que esses impactos sejam percebidos na área estudada. Além disso, esses fatores, assim como o acúmulo de lixo, podem ser mitigados com estratégias eficientes de gestão.

Apenas sete impactos foram considerados nessa avaliação: (1) visibilidade turística, (2) padronização da estrutura turística, (3) aumento da visitação como justificativa para menor probabilidade de volta dos narcotraficantes e mais segurança, (4) aumento da visitação como justificativa para mais oportunidades de emprego e renda para moradores locais, (5) acúmulo de lixo, (6) erosão e compactação das trilhas e (7) depredação de sinalização (Quadro 1).

A intensidade dos impactos foi avaliada usando uma escala de Likert de 5 pontos que varia entre -2 , impacto extremamente negativo, a +2 , impacto extremamente positivo. O zero indica que o componente não sofre alterações quando em comparação com o cenário atual. Os valores alocados na Tabela 1 são valores médios obtidos nas entrevistas e nos grupos de discussão que incluíram os alunos, atores sociais interessados e técnicos da SMAC e os totais finais foram obtidos de uma simples soma dos valores médios alocados para cada impacto.

Os resultados dessa avaliação indicam que o futuro dessas UCs está diretamente relacionado com o manejo do uso público. Sem manejo (cenário laissez-faire), como acontece na atualidade, é provável que a área seja retomada pelos narcotraficantes, voltando a ser palco da violência carioca. Todavia, com interferências estratégicas, esse e outros impactos negativos, como acúmulo de lixo, erosão e compactação do solo e depredação da sinalização, podem ser evitados. Além disso, os impactos positivos, como aumento de oportunidades de emprego e renda para os 
moradores do Rio, podem ser intensificados. Assim, chegou-se a conclusão que o cenário ideal é o que prevê a maior quantidade de intervenções, isto é, a junção das unidades num único parque com planos de manejo e de uso público atualizados e com ações constantes de gestão. Este Parque é o denominado Parque Natural Municipal da Paisagem Carioca.

Tabela 1: Avaliação de Impactos Ambientais.

Table 1: Environmental impact assessment.

\begin{tabular}{|l|c|c|c|c|c|}
\hline \multirow{2}{*}{ Impactos } & \multicolumn{7}{|c|}{ Cenários } \\
\cline { 2 - 6 } & $\mathbf{1}$ & $\mathbf{2}$ & $\mathbf{3}$ & $\mathbf{4}$ & $\mathbf{5}$ \\
\hline visibilidade turística & 0 & +2 & 0 & 0 & -2 \\
\hline padronização da estrutura turística & 0 & +2 & +1.2 & +1.2 & -1.8 \\
\hline $\begin{array}{l}\text { aumento da visitação - menor } \\
\text { probabilidade de volta dos } \\
\text { narcotraficantes e mais segurança }\end{array}$ & 0 & +2 & +1.3 & +0.8 & -2 \\
\hline $\begin{array}{l}\text { aumento da visitação - mais } \\
\text { oportunidades de emprego e renda para } \\
\text { moradores locais }\end{array}$ & 0 & +2 & +0.8 & +1 & -1.9 \\
\hline acúmulo de lixo & & & & & \\
\hline erosão e compactação das trilhas & -1.8 & +0.8 & +1.1 & +1.2 & +1.9 \\
\hline sinalização (depredação ou conservação) & -2 & +0.8 & +0.9 & +1.1 & +1.8 \\
\hline total & $-\mathbf{5 . 8}$ & $\mathbf{+ 1 0 . 5}$ & $\mathbf{+ 6 . 3}$ & $+\mathbf{+ 6 . 3}$ & $\mathbf{- 4}$ \\
\hline
\end{tabular}

Dos totais alcançados observa-se que o cenário 2, qual seja a junção das três unidades num Parque com um único plano de manejo e de uso público, alcançou a melhor avaliação, quase o dobro dos 2 cenários que ocupam a segunda posição.

\section{Conclusões}

No Brasil, historicamente as unidades de conservação foram criadas especialmente para preservar os recursos naturais, evitando-se, sempre que possível, qualquer forma de uso da natureza. Acreditava-se que baixo essa redoma legal, a natureza estaria a salvo da sociedade. Mas estudos realizados nas últimas décadas indicaram exatamente o oposto, isto é, que esses 'vazios' populacionais davam espaço à prática de atividades ilícitas como caça, captura e tráfico de animais silvestres, extração de recursos (madeira, minerais, palmito, etc.) e, no caso extremo do Rio de Janeiro, abrigo aos narcotraficantes. Nesse contexto, a percepção sobre o turismo e a visitação pública de forma geral começou a mudar. Os visitantes estão começando a ser vistos como 'aliados' na fiscalização, pois, assim como os gestores, querem que a qualidade ambiental se mantenha ou melhore e estão dispostos a controlar (fotografar e denunciar) os desusos nas áreas naturais (MORAES; IRVING, 2013). O estudo descrito se fundamentou filosoficamente nessa segunda percepção, segundo a qual a visitação poderia ser utilizada como uma das mais importantes ferramentas de ocupação dos espaços naturais e de monitoramento de atividades ilícitas. 
Nesse caso específico, além dessa ter sido uma premissa importante, - estudo também partiu do fato dessa ser uma área reflorestada com comprovada capacidade de resiliência. Isto é, diferentemente de áreas com alta fragilidade ecológica, se estratégias de gestão equivocadas forem colocadas em prática e se houver monitoramento constante, então será possível rapidamente mitigar os impactos negativos evidenciados, fato que confere à área um importante papel de 'laboratório'.

Nesse contexto, este estudo indicou que o ideal é transformar a área num parque, pois isso aumentaria significativamente a visitação e isso é importante, pois um maior número de pessoas circulando pelas trilhas dificultaria o retorno dos narcotraficantes. Além disso, se ampliariam as possibilidades de emprego e renda das populações do entorno, especialmente para os moradores das comunidades (carentes) como Chapéu Mangueira e Tabajara. Em contrapartida, se espera que essas mesmas comunidades apoiem a proteção da natureza. Todavia, a ampliação da visitação possibilita atividades de educação ambiental, como já acontece no Morro São João, e quantas mais pessoas visitarem a área, maior a pressão da sociedade para proteger essa unidade. Um último fator que fundamentou a decisão de ampliar a visitação foi o fato de diferentes estudos indicarem que a população está cada vez mais sedentária e com sobrepeso, e desta forma ter-se-á uma alternativa saudável de lazer para os cariocas.

Foi baixo essas premissas e com os resultados do estudo apresentado, que também inclui indicadores, padrões de qualidade e estratégias de monitoramento, que em 05 de Junho de 2013 o prefeito do Rio de Janeiro criou o Parque Natural Municipal da Paisagem Carioca. Os estudos para o desenvolvimento do Plano de Manejo estão em andamento e são fundamentais no longo prazo. Mas no curto e médio prazos, enquanto a área ainda carece desse conhecimento, os gestores vão manejando os recursos com as instruções estabelecidas para que a visitação ocorra com mínimos impactos negativos na dinâmica da gestão adaptativa, pela qual o monitoramento é a principal fonte de informações.

\section{Referências bibliográficas}

ARAÚJO, M.A.R. Sistema Nacional de Unidades da Natureza (SNUC). In: NEXUS (Org.). Unidades de conservação no Brasil: O caminho da gestão para resultados. São Carlos: Rima, p. 113-124, 2012.

BRASIL, Lei 9985/00 que Institui o Sistema Nacional de Unidades de Conservação da Natureza.

BURKOWSKI, R.; VILAS BOAS,A.A. Território e desenvolvimento turístico: possíveis contribuições de um mosaico de unidades de conservação. Revista Brasileira de Ecoturismo, v. 7, n.2, p. 322-343, 2014.

CEBALLOS-LASCURAIN, H. Introdução: O Ecoturismo como um fenômeno mundial. In: LINDBERB, H.; HAWKINS, D.E. (Org.). Ecoturismo, um guia para planejamento e gestão. Tradução de Leila Cristina de M. Darin, revisão técnica de Oliver Hillel.5 Ed.São Paulo: SENAC, 2005, p. 23-30. 
DECRETO 37.231. Cria o Parque Natural da Paisagem Carioca e dá outras providências. Disponível em: <https://www.leismunicipais.com.br/a/rj/r/riode-janeiro/decreto/2013/3723/37231/decreto-n-37231-2013-cria-o-parquenatural-municipal-paisagem-carioca-e-da-outras-providencias-2013-0605.html>. Acesso: em 29 Out. 2013.

DOUROJEANNI, M.J.; PÁDUA, M.T.J. Biodiversidade: A Hora Decisiva. Curitiba, UFPR, FBPN, 308 p., 2001.

FOGLIATTI, M. C.; CAMPOS, V. B. G.; FERRO, M. A. C., SINAY. L.; CRUZ, I. Sistemas de Gestão Ambiental Para Empresas Prestadoras de Serviços. Rio de Janeiro : Editora Interciencia Ltda, 2008, v.1. 1a edição. p.128.

FUNBIO, Fundo Brasileiro de Biodiversidade. Fortalecimento e implantação da gestão do uso público para o incremento da visitação nos parques estaduais do Rio de Janeiro. Termo de Referencia N0 04/2012.

MINARI, M. de L.; RABINOVICI, A. Diálogo, participação e projetos de turismo com comunidades em Unidades de Conservação na Amazonia Brasileira. Revista Brasileira de Ecoturismo, v. 7, n. 2, p. 44-66, 2014.

MINISTÉRIO DO TURISMO. Dados e Fatos. Disponível em: $<$ http://www.dadosefatos.turismo.gov.br/dadosefatos/geral interna/fontes e statisticas>. Acesso em: 29 Out. 2013.

MORAES, E. A.; IRVING, M. A. Ecoturismo: encontros e Desencontros na reserva extrativista do Cazumbá, Iracema $(A C)$. Revista Brasileira de Ecoturismo, V.6, n.3, pp 78-757, 2013

MOSAICO CARIOCA. Blog do Mosaico Carioca de áreas protegidas. Disponível em: http://mosaico-carioca.blogspot.com.br/. Acesso em: 29 Out. 2013.

OLIVEIRA, C.A.F. de; BLOS, W. da S. Ecoturismo: desenvolvimento, comunidades tradicionais e participação. Caderno Virtual de Turismo, RL, v. 12, n. 2, p. 137-151, 2012.

PAIVA, N.V.M. de; ARAÚJO, M.V.P. Gestão participativa e ecoturismo em unidades de conservação: a voz da comunidade através do Conselho Gestor. Anais do IX Congresso Nacional de Ecoturismo e V Encontro Interdisciplinar de turismo em unidades de conservação, São Paulo, 2013. Revista Brasileira de Ecoturismo. V.6, n.4, p.11-26, 2013.

PELLIN, A.; CARVAlHO, G. de; REIS, J. G.; PELLIN, A. Gestão de uso público em parques urbanos: o caso do Parque Estadual da Pedra Branca (RJ). Revista Brasileira de Ecoturismo, v. 7, n. 2, p.344-373, 2014.

PINHEIRO, M.R. Recomendações para reconhecimento e implementação de mosaicos de áreas protegidas. Brasília, D. F. GTC, 2010.

PITT, B.; BOULLE, T. Growing together: thinking and practice of urban nature conservators, SANBI Cape Flats Nature, Cape Town, p. 156, 2010.

SALVATI, S. S. Planejamento do Ecoturismo. In: MITRAUD, S (Org.) Manual de ecoturismo de base comunitária: ferramentas para um planejamento responsável. Brasília: WWF, p. 33-88, 2013. 
SINAY, L. From Chaos to Management: Modelling Cultural and Environmental Change, 2008, 380. Tese (Doutorado em Gestão de recursos Naturais), The University of Queensland, Brisbane, 2008.

SINAY, L. et al. Plano de Uso Público: Uma proposta estratégica para o ótimo aproveitamento turístico dos Morros da Babilônia, São João, Leme e Urubu e do Parque Estadual da Chacrinha. Universidade Federal do estado do Rio de Janeiro - UNIRIO. Rio de Janeiro, 2012.

TEIXEIRA, P.R.; MICHELIN, R. L. Monitoramento de impactos ambientais na trilha do Salto Ventoso, Farroupilha-RS. Turismo Visão e AçãoEletrônica, v. 15, n. 2, p. 295-305, 2013.

URANI, A.; GIAMBIAGI, F. Rio: a hora da virada. Rio de Janeiro: Elsevier, 2011. 272p.

WANDERLEY-FILHA, I.; AZEVEDO, F. F. de; NÓBREGA, W.R. de, ALBUQUERQUE, J. C. Planejamento e Políticas Públicas do Turismo: uma discussão teórica no contexto das unidades de conservação no Brasil. Anais do IX Congresso Nacional de Ecoturismo e V Encontro Interdisciplinar de turismo em unidaes de conservação, São Paulo, 2013. Revista Brasileira de Ecoturismo. V.6, n.4, p.27-44, 2013.

\section{Agradecimentos}

As autoras agradecem aos alunos de Planejamento Ambiental do Turismo da Universidade Federal do Estado do Rio de Janeiro - UNIRIO pela coleta de dados: Amanda Louise, Bianca Lima, Carla Guedes, Cindy Diniz, Daniel Braga, Darlan Coelho, Debora Brum, Deborah Mendes, Gabriele Ferreira, Juliana Kupfer,, Kim Monteiro, Larissa Zanchetta, Louise Machado, Luiz Saldanha, Monique Braz, Núbia Rosinski, Rodrigo Chaves, Taiane Penedo, Victor Pedote e Gabriella Revelles Brancaccio.

\section{Notas:}

${ }^{1}$ Os 23 Mosaicos de Áreas Protegidas existentes são: Mosaico Tucurui (PA), Mosaico Apuí (AM), Mosaico Serras da Capivara e Confusões (PI), Mosaico Marinho (SP/PR), Mosaico Litoral Sul do Estado de São Paulo e Litoral do Estado do Paraná (Lagamar) (SP/PR), Mosaico Serra da Bocaina (SP/RJ), Mosaico Mata Atlântica Central Fluminense (RJ), Mosaico Serra da Mantiqueira (SP/RJ/MG), Mosaico Jureia Itatins (SP), Mosaico Serra São Jose (MG), Mosaico Jacupiranga (SP), Mosaico das llhas e Áreas Marinhas Protegidas do Litoral Paulista (SP), Mosaico Grande Sertão Veredas Peruaçu (MG/GO/BA), Mosaico do Manguezal da Baía de Vitória (ES), Mosaico do Espinhaço (MG), Mosaico Baixo Rio Negro (AM), Mosaico da Foz do Rio Doce (ES), Mosaico Mico-Leão-Dourado (RJ), Mosaico Extremo Sul da Bahia (BA), Mosaico da Amazônia Meridional (AM), Mosaico Carioca (RJ), Mosaico do Paranapiacaba (SP), Mosaico Oeste do Amapá e Norte do Pará (AP/PA). 
Laura Sinay: Universidade Federal do Estado do Rio de Janeiro, Rio de Janeiro, RJ, Brasil.

E-mail: laurasinay@gmail.com

Link para o currículo Lattes: http://lattes.cnpq.br/1227278208156191

Maria Cristina Fogliatti de Sinay: Universidade do Grande Rio, Rio de Janeiro, RJ, Brasil.

E-mail: cristinasinay@gmail.com

Link para o currículo Lattes: http://lattes.cnpq.br/4705136602818227

Ingrid Almeida de Barros Pena: Universidade Federal Rural do Rio de Janeiro, Seropédica, RJ, Brasil.

E-mail: ingrid.pena@gmail.com

Link para o currículo Lattes: http://lattes.cnpq.br/2600359724661812

Data de submissão: 31 de outubro de 2013

Data de recebimento de correções: 03 de julho de 2014

Data do aceite: 25 de julho de 2014

Avaliado anonimamente 